\title{
Correction to: Hypoxia modulation by dual-drug nanoparticles for enhanced synergistic sonodynamic and starvation therapy
}

Jingxue Wang' ', Ju Huang' ', Weichen Zhou' ', Jiawen Zhao², Qi Peng ${ }^{3}$, Liang Zhang², Zhigang Wang², Pan $\mathrm{Li}^{2}$ and Rui $\mathrm{Li}^{\mathrm{i}^{*}}$

\section{Correction to: J Nanobiotechnol (2021) 19:87}

https://doi.org/10.1186/s12951-021-00837-0

Following publication of the original article [1], the authors identified an error in Fig. 10.
The original version of figure (Fig. 10) is provided in this correction.

The original article has been revised. to the material. If material is not included in the article's Creative Commons licence and your intended use is not permitted by statutory regulation or exceeds the permitted use, you will need to obtain permission directly from the copyright holder. To view a copy of this licence, visit http://creativecommons.org/licenses/by/4.0/. The Creative Commons Public Domain Dedication waiver (http://creativecommons.org/publicdomain/zero/1.0/) applies to the data made available in this article, unless otherwise stated in a credit line to the data. 


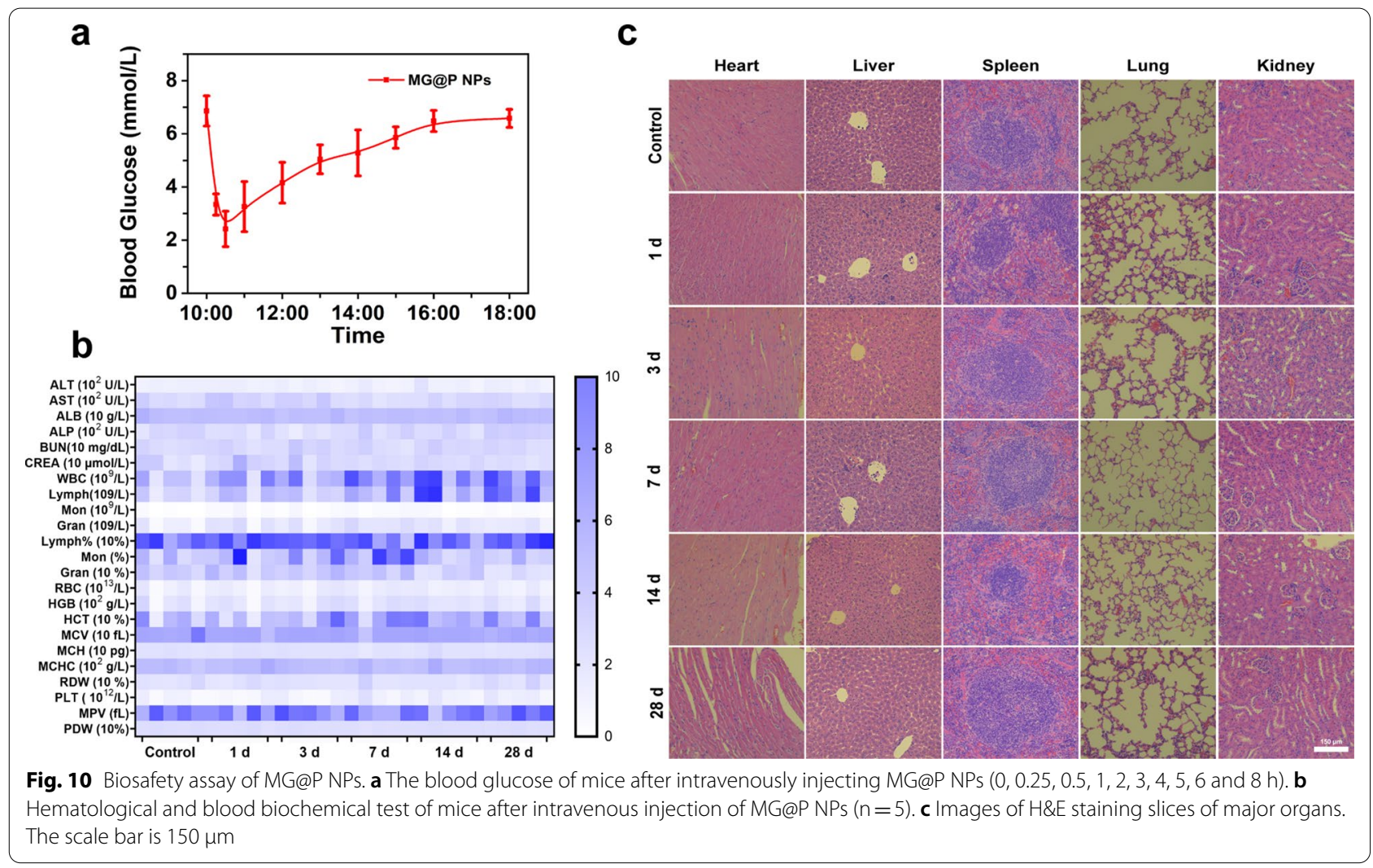

\section{Author details}

'Department of Ultrasound, The Third Affiliated Hospital, Chongqing Medical University, Chongqing 400010, People's Republic of China. ${ }^{2}$ Chongqing Key Laboratory of Ultrasound Molecular Imaging, Institute of Ultrasound Imaging, The Second Affiliated Hospital, Chongqing Medical University, Chongqing 400010, People's Republic of China. ${ }^{3}$ University-Town Hospital, Chongqing Medical University, Chongqing 401331, People's Republic of China.

Published online: 30 September 2021

\section{Reference}

1. Wang J, Huang J, Zhou W, Zhao J, Peng Q, Zhang L, Wang Z, Li P, Li R. Hypoxia modulation by dual-drug nanoparticles for enhanced synergistic sonodynamic and starvation therapy. J Nanobiotechnol. 2021;19:87. https://doi.org/10.1186/s12951-021-00837-0.

\section{Publisher's Note}

Springer Nature remains neutral with regard to jurisdictional claims in published maps and institutional affiliations. 